\title{
Research on the Cultivation Model of Collaborative Innovative Talents for Interdisciplinary Engineering Training
}

\author{
Jianhua Cao ${ }^{\text {a }}$, Xiaoqin Liu ${ }^{\text {b }}$, Guozhang Jiang ${ }^{c}$, Cui Zheng ${ }^{d}$, Xiang Liu ${ }^{e}$, \\ Xiong $\mathrm{Bao}^{f}$
}

\author{
Engineering Training Center, Wuhan University of Science and Technology, Wuhan, China \\ a caojianhua39@wust.edu.cn, b liuxiaoqin@wust.edu.cn, cjiangguozhang@wust.edu.cn, \\ d zhengcui@wust.edu.cn, e liuxiang@wust.edu.cn, ${ }^{\dagger}$ baoxiong@wust.edu.cn
}

\begin{abstract}
Through school-enterprise cooperation, jointly formulate industry-university cooperation and collaborative education programs, build innovative talent training models and curriculum systems, strengthen internship training, highlight practical capabilities, and cultivate the combination of knowledge and skills, technology and management, ability and quality combining applied talents. Establish cross-disciplinary and professional innovation courses, explore the establishment of a new mechanism for cross-faculty, cross-disciplinary, and cross-professional training of innovative and entrepreneurial talents, and promote the transformation of talent training from a single type of discipline to a multi-disciplinary integration.
\end{abstract}

Keywords: Interdisciplinary; Engineering Training; Industry-University-Research Cooperation; Collaborative Innovation; Training Model.

\section{Introduction}

At the National Education Conference, president Xi Jinping pointed out that it is necessary to promote collaborative innovation of industry, university and research, actively devote itself to the implementation of innovation-driven development strategies, and focus on cultivating innovative, compound, and application-oriented talents [1]. With the release of Tianjin University's "CoherentCollaborative-Interdisciplinary-Innovation" (CCII) and "Six Excellence and One Top" program 2.0 and other undergraduate teaching reform plans, colleges and universities have set off an upsurge of engineering education reform [2-5]. Cultivating interdisciplinary and interdisciplinary innovative talents is not only the need of national and regional economic and social development, but also the needs of adapting to the new engineering and new economy, and it is an important manifestation of the mission of talent training in universities $[6,7]$. The new engineering discipline embodies a great integration, first of all disciplines and majors, interdisciplinary research centers, professional cluster construction, etc.; secondly, it embodies a great integration of talent capabilities, cross-industry, integration, integration, and innovation. New engineering is the product of interdisciplinary, and it is also an important way for universities to break the existing stereotypes of talent training [8]. Therefore, colleges and universities should build a new inter-disciplinary, inter-professional, and inter-academic talent training system, set up interdisciplinary courses, optimize professional structure, etc. to enhance students' innovative ability [9].

Many scholars have conducted in-depth research on the issue of interdisciplinary talent training for different majors. Wang $\mathrm{Na}$ explored the ways of training innovative and entrepreneurial talents in financial engineering from the aspects of interdisciplinary and inter-professional innovative and entrepreneurial talent training goals, curriculum system, teaching mode, teacher construction and inter-faculty alliances [10]; Taking the training of interdisciplinary innovative talents in Sichuan University as an example, Su Yonglin discussed the thinking and understanding of the cultivation of innovative talents, and innovatively proposed the construction of an interdisciplinary and compound talent training model, and demonstrated the practice and exploration of interdisciplinary innovative talent cultivation [11]; Aiming at the shipping major, Ge Hong explored the training model, training system and training mechanism of innovative shipping talents for the construction of interdisciplinary cooperation through a series of measures such as deepening the concept of interdisciplinary 
cooperation, forming relevant teams, and building corresponding platforms.[12] . Existing research is only conducted on the issues of interdisciplinary talent training and teaching teams in finance, shipping and other majors, and has achieved good practical application effects, but the research on the engineering training center is rarely involved.

As an important base for colleges and universities to carry out engineering technology, process training and engineering innovation practice for college students, it is an important education link for cultivating students' practical ability and innovative consciousness. It is important for improving the overall quality of students and cultivating high-quality, high-level new century. Engineering and technical talents play an irreplaceable role in other courses. At the same time, since the actual training targets are all science and engineering students in the school, it has obvious interdisciplinary characteristics. As an advanced manufacturing method, laser processing has been promoted and popularized in many industrial fields such as welding, cutting, engraving and heat treatment. It is the key development target of my country's new round of scientific and technological revolution and industrial upgrading. However, college graduates under the current training model cannot meet the needs of social enterprises. Therefore, taking the actual needs of the enterprise as the guide, integrating laser processing technology with engineering training, and exploring cross-disciplinary engineering training talent training models are of great significance to cultivating "new engineering" talents facing social needs.

In this context, with Guangzhou Huazhizun Optoelectronics Technology Co., Ltd. to carry out indepth engineering training collaborative education cooperation based on laser processing technology, jointly explore the interdisciplinary engineering training industry-university-research collaborative innovation talent training model, update the talent training program, and innovate the curriculum system, Strengthen internship training, highlight practical ability, cultivate application-oriented talents who combine knowledge and skills, technology and management, and ability and quality.

\section{Construction of the " $3+N$ " Talent Training Model for Interdisciplinary Engineering Training}

Adapting to the new economy and serving the new economy are important responsibilities of colleges and universities, but in order to cultivate the talents needed by the new economy, it is necessary to reform the existing engineering talent training model, and build a talent training model based on cross-discipline integration based on the needs of enterprises. Only in this way can we truly cultivate a group of high-quality innovative talents who have strong practical ability and support the new economy. Aiming at the engineering training center, an interdisciplinary " $3+\mathrm{N}$ " talent training model is proposed, as shown in Figure 1.

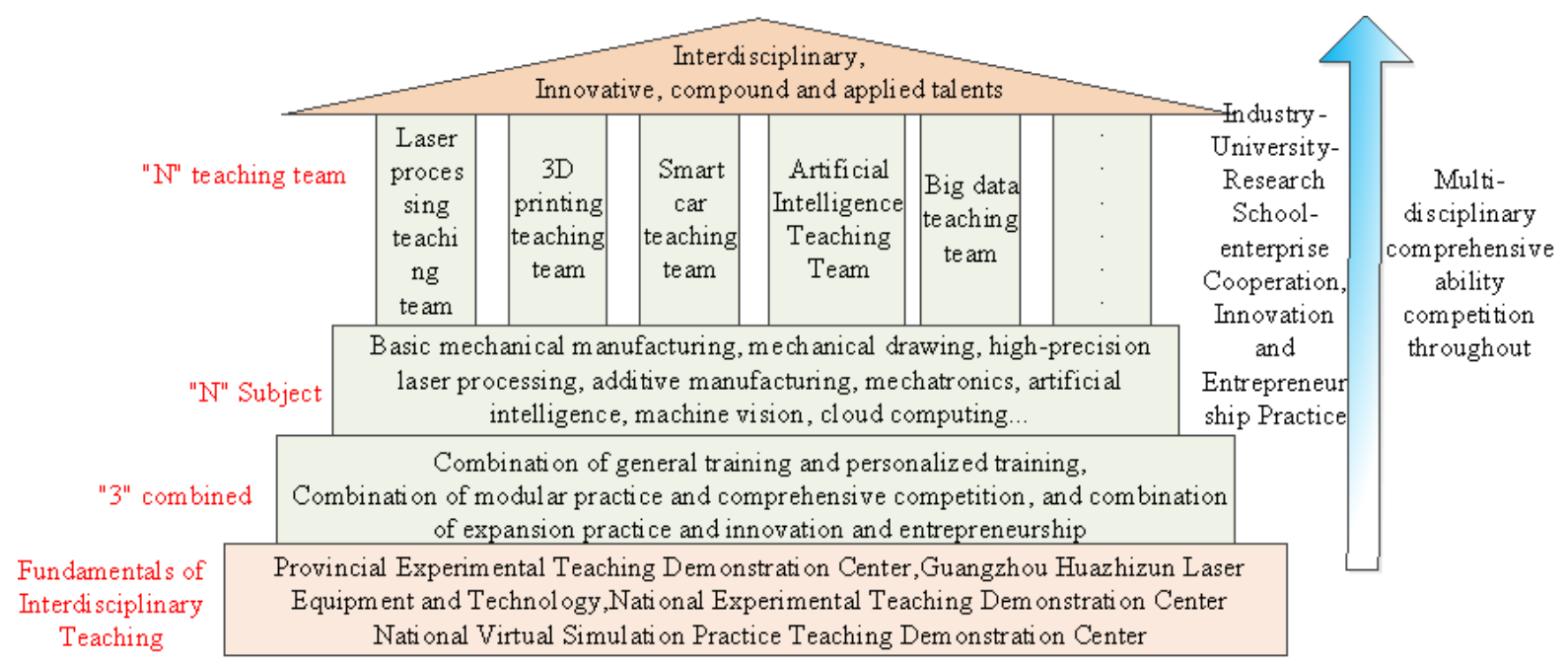

Figure 1. "3+N" interdisciplinary engineering training model 
"3" means "three combinations": adhere to the combination of basic training and individualized training, modularized training and comprehensive competition, and expansion of training and innovation and entrepreneurship. The "three-in-one combination" is to reflect the characteristics of all-round, individualized, and endogenous engineering training, to ensure that students have the opportunity to independently choose personalized training content and courses based on mastering basic practical skills, and build them under the guidance of teachers. I am interested in the modular system, and realize the improvement of comprehensive practical ability by participating in comprehensive competitions, such as the National Comprehensive Ability Competition of Engineering Training for College Students. For students with outstanding abilities, they can continue to expand and train, and participate in the "Internet + " college student innovation and entrepreneurship competition, the "Creating Youth" National College Student Entrepreneurship Competition and other high-level innovation and entrepreneurship competitions with wide influence to cultivate students' comprehensive quality and "double innovation" capabilities.

"N" has two meanings, namely "N interdisciplinary" and "N interdisciplinary teaching team". "N cross-disciplines" are the organic integration of science and engineering related disciplines such as mechanics, electronics, information, computer, materials, etc., coordinate the formulation of undergraduate courses, school system settings, and training programs, and adopt scientific research practices, assessment management, and graduation. Thesis and other means cultivate all-round new engineering leaders who can meet future challenges and lead the development of the industry. At the same time, the undergraduate scientific research training plan is used as the carrier to help students improve their comprehensive quality, innovation awareness and innovation ability, and master a solid theoretical foundation and systematic professional knowledge.

"N interdisciplinary teaching teams" build $\mathrm{N}$ interdisciplinary teaching teams on the basis of "N interdisciplinary" combined with specific scientific research projects. Help students develop independent scientific research capabilities, assess their scientific research capabilities through a multi-faceted and multi-method evaluation system, and train students in a broad and open manner through the intersection of scientific research teams, and implement a multi-tutorial system of scientific research team cooperative guidance, so that there are Potential students can fully broaden their academic horizons and lay the foundation for future scientific research, innovation and entrepreneurship.

\section{Construction of the Interdisciplinary "Three Vertical and Three Horizontal" Engineering Training Curriculum System}

Existing engineering training is mainly based on traditional manufacturing technologies, such as fitter, general lathe, general milling, heat treatment, CNC lathe, CNC milling, electrical and electronics, etc. The new economy requires vigorous development of emerging engineering majors and characteristic professional clusters related to new industries. Such as laser technology, big data, artificial intelligence, cloud computing, Internet of Things, etc. The current engineering training curriculum system cannot meet the requirements of new engineering talent training, and it is difficult to meet the requirements of advanced manufacturing and social transformation and upgrading. The current curriculum system needs to be reconstructed. Therefore, under the " $3+\mathrm{N}$ " interdisciplinary engineering training model, the project team constructed a "three vertical and three horizontal" engineering training teaching curriculum system, as shown in Figure 2.

Aiming at the " $3+\mathrm{N} "$ interdisciplinary engineering training model, the engineering training teaching system is divided into 3 levels (three horizontals), and each level of teaching is divided into teaching content, teaching methods and teaching objectives (three verticals): The first level is basic ability training, using visualization, information, and standardized teaching methods to cultivate students' basic experimental skills, taking into account common needs and special requirements, and designing a systematic and complete professional basic experimental module; The second level is comprehensive design experimental ability training, which adopts a personalized and open teaching 
method. Through the construction of experimental practice modules such as curriculum design, comprehensive design and special seminars, the integration of knowledge between different knowledge points and different courses is realized, and Knowledge reconstruction and knowledge integration, to further consolidate the basic concepts, basic principles and analysis methods of the students' professional knowledge, cultivate the comprehensive application of the learned knowledge to analyze and solve problems, realize the active use of knowledge, and cultivate students' self-study ability, Thinking ability, practical viewpoint and teamwork ability; The third level is innovative practical ability training, which adopts engineering and collaborative teaching methods. It is the highest level of engineering practical ability and engineering literacy training. It mainly relies on the high-quality software and hardware resources and teachers of the training center. Innovation and entrepreneurship projects (college student innovation training program projects, open experimental training projects, etc.), subject competitions (college student electronic design competitions, mathematical model competitions, etc.), and scientific research as the carrier, adopt a flexible organizational model to cultivate students' innovative ability and thinking ability, Cooperation ability, scientific research ability and engineering consciousness.
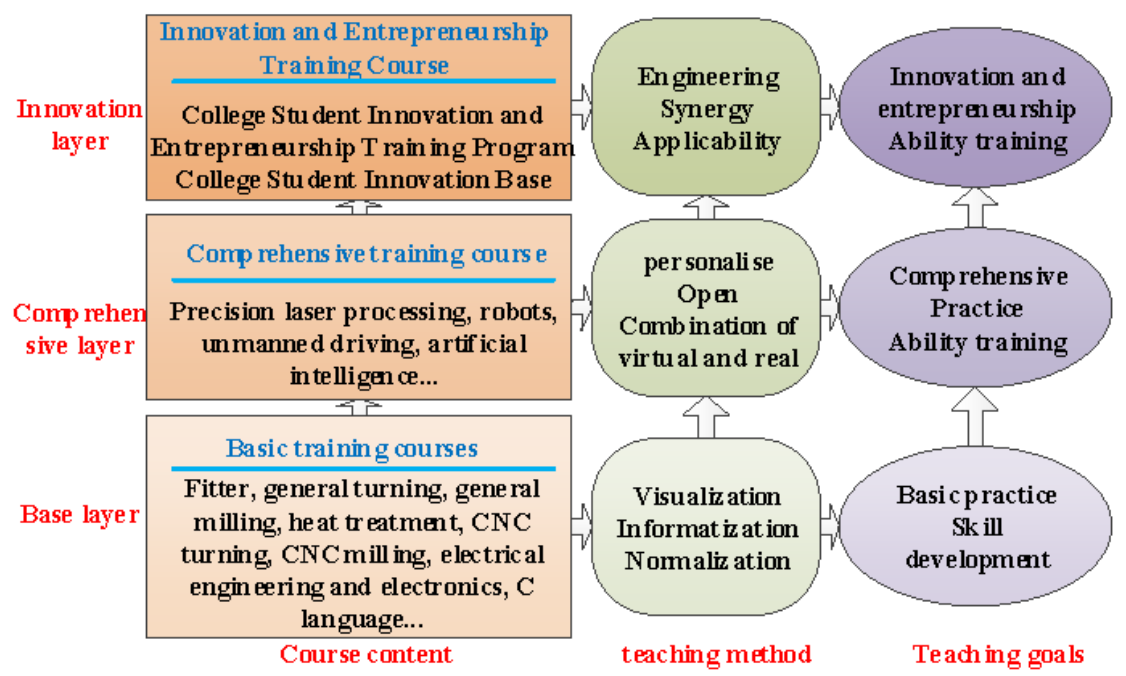

Figure 2. Interdisciplinary 'Three Vertical and Three Horizontal' Engineering Training Course System

In the curriculum system, comprehensive intellectual and non-intellectual factors are considered at the same time. The curriculum includes three dimensions of knowledge, ability, and quality. It reserves the knowledge of interdisciplinary fields, cultivates the ability of multidisciplinary research and the spirit of interdisciplinary cooperation, so that the cultivated Talents have multidisciplinary thinking, compound knowledge, innovative ability and engineering qualities.

\section{Summary}

The Engineering Training Center combined with the equipment characteristics of Huazhizun Laser, laser engraving and cutting technology, and teacher guidance, etc., to jointly formulate industryuniversity cooperation and collaborative education programs, update talent training programs, innovate curriculum systems, strengthen internship training, and highlight practical operations Ability to cultivate applied talents who combine knowledge and skills, technology and management, and ability and quality. Establish cross-disciplinary and professional innovation courses, explore the establishment of a new mechanism for cross-faculty, cross-disciplinary, and cross-professional training of innovative and entrepreneurial talents, and promote the transformation of talent training from a single type of discipline to a multi-disciplinary integration. The main results are as follows: 1). Establish an interdisciplinary engineering training " $3+\mathrm{N} "$ production-university-research 
collaborative innovation talent training model, which embodies the omni-directional, personalized and endogenous engineering training characteristics, and promotes the humanities and scientific literacy of students through general education Fully developed. 2). Combined with the characteristics and technology of Huazhizun laser equipment, reconstruct the traditional engineering training course system, integrate high-precision laser, big data, artificial intelligence and other majors, and cultivate innovative, creative, interdisciplinary, comprehensive, and future-oriented individual diversification Of new engineering talents.

\section{Acknowledgments}

This work was partially supported by the Ministry of Education Industry-University Cooperation Collaborative Education Project (201902025029, 202002023001, Research on the Cultivation Model of Collaborative Innovative Talents for Interdisciplinary Engineering Training) and Wuhan University of Science and Technology School-level Teaching and Research Project (Yjg202015, 2020X077, 2020X086,2019X085, 2019Z005).

\section{References}

[1] Xi Jinping. Important speech at the General Education Conference [EB/OL]. China Government Network, http://www.gov.cn/2018-09-10.

[2] The Fudan Consensus on the Construction of "New Engineering Course" of the Higher Education Department of the Ministry of Education [J]. Research in Higher Engineering Education, 2017 (1): 10-11.

[3] The "New Engineering" construction action line of the Higher Education Department of the Ministry of Education ("Tianda Action") [J]. Higher Engineering Education Research, 2017 (4): 24-25.

[4] Department of Higher Education, Ministry of Education. New Engineering Construction Guide ("Beijing Guide") [J]. Higher Engineering Education Research, 2017 (6): 20-21.

[5] Guangming Daily. Engineering innovation is both a "big" and a big thing [EB/OL]. [2019-04-29]. http:// epaper. gmw.cn/gmrb/html/2019 -04/29/nw.D110000gmrb_20190429_3-16.htm.

[6] Jiao Lei. Analysis on the Trend of Interdisciplinary Organization of Well-known Foreign Universities[J]. Research in Higher Engineering Education, 2018, (3): 124-129.

[7] Vaughn Pinxit. Navigating the Methodology of an Interdisciplinary Art and Design Practice with Conscious Bridging[J]. International Journal of Art \& Design Education, 2019: 416-429.

[8] Yu Guowen, Cao Yiming. Interdisciplinary Teaching Research: Taking Finnish Phenomenon Teaching as an Example [J]. Foreign Elementary and Secondary Education, 2017, (7): 57-63.

[9] Su Yonglin, Zhang Jianbing, Dai Rui. Exploration and practice of interdisciplinary innovative talent training model[J]. Leather Science and Engineering, 2019, 29(01):77-81.

[10] Wang Na. Research on the Cultivation Model of Interdisciplinary and Interdisciplinary Innovative and Entrepreneurial Talents[J]. China Metallurgical Education, 2019(2):57-58.

[11] Su Yonglin, Zhang Jianbing, Dai Rui, etc. The exploration and practice of interdisciplinary innovative talent training model[J]. Leather Science and Engineering, 2019, 29(01):77-81.

[12] Ge Hong, Lu Changli. Theoretical research on the training mode, training system and training mechanism of innovative shipping talents through interdisciplinary cooperation $[\mathrm{J}]$. Market Weekly (Theoretical Research), 2018, (03), 134-135+154. 